\title{
EXPRESSION OF THE pS2 PEPTIDE IN NORMAL HUMAN GLANDULAR ENDOMETRIUM DURING THE MENSTRUAL CYCLE: A POSSIBLE FUNCTION
}

\author{
P. D. RYE*, K. DOOKERAN AND R. A. WALKER \\ University of Leicester, Breast Cancer Research Unit, Glenfield General Hospital, Groby Road, \\ Leicester LE3 9QP, UK
}

KEY WORDS pS2 Menstrual cycle Endometrium

Since the identification of pS2 mRNA in the MCF-7 human breast cancer cell line (Masiakowski et al. 1982), and its demonstrated response to oestrogen stimulation (Kida et al. 1989; Brown et al. 1984), a great deal of interest has been focused on this small polypeptide. Although a number of studies have demonstrated pS2 expression in the breast, few studies have documented $\mathrm{pS} 2$ expression in other tissues. Glandular epithelium of the endometrium, like the breast, is subject to hormonal fluctuations directly related to the organ-specific function. Those studies that have included normal endometrial epithelium, did not detect the $\mathrm{pS} 2$ peptide (Rio et al. 1988; Chambon et al. 1984; Piggot et al. 1991). In endometrial adenocarcinoma, pS2 has been detected but its expression was notably variable (Henry et al. 1991), or very weak (Wysocki et al. 1990). Hormone regulated proteins specifically expressed by glandular endometrium during the menstrual cycle may be of value in the treatment of infertility, acting as markers for the functional readiness of endometrium for implantation. A previous study, evaluating the expression of a number of breastassociated markers in endometrial tissues, showed there to be menstrual cycle phase-specific patterns of immunostaining implicating hormonal regulatory mechanisms (Rye et al. 1993). In view of this, and the reported oestrogen responsiveness of pS2, we have assessed its expression in endometrial tissues from different stages of the menstrual cycle to determine if there is oestrogen regulation of $\mathrm{pS} 2$ in this tissue. If so, $\mathrm{pS} 2$ could be of value as a marker of functioning endometrium in the menstrual cycle.

In this study 21 tissues were obtained from dilatation and curettage (D and C) cases, e.g. investigation for dysmenorrhoea, association with laporascopic sterilization, and infertility investigation. Cases were selected on the grounds of having no apparent endocrinological problems and no local organic pathologies. All cases were obtained from patients in the 20 to 30 -year-old age group, with a regular cycle history. Tissues were fixed in formaldehyde and paraffin-wax embedded. Endometrial specimens were dated from the last menstrual period and were only used in the study if there was corroboration by independent histological dating which followed standard histological criteria (Hendrickson and Kempson, 1980). The

*Addressee for correspondence. 
Reactivity

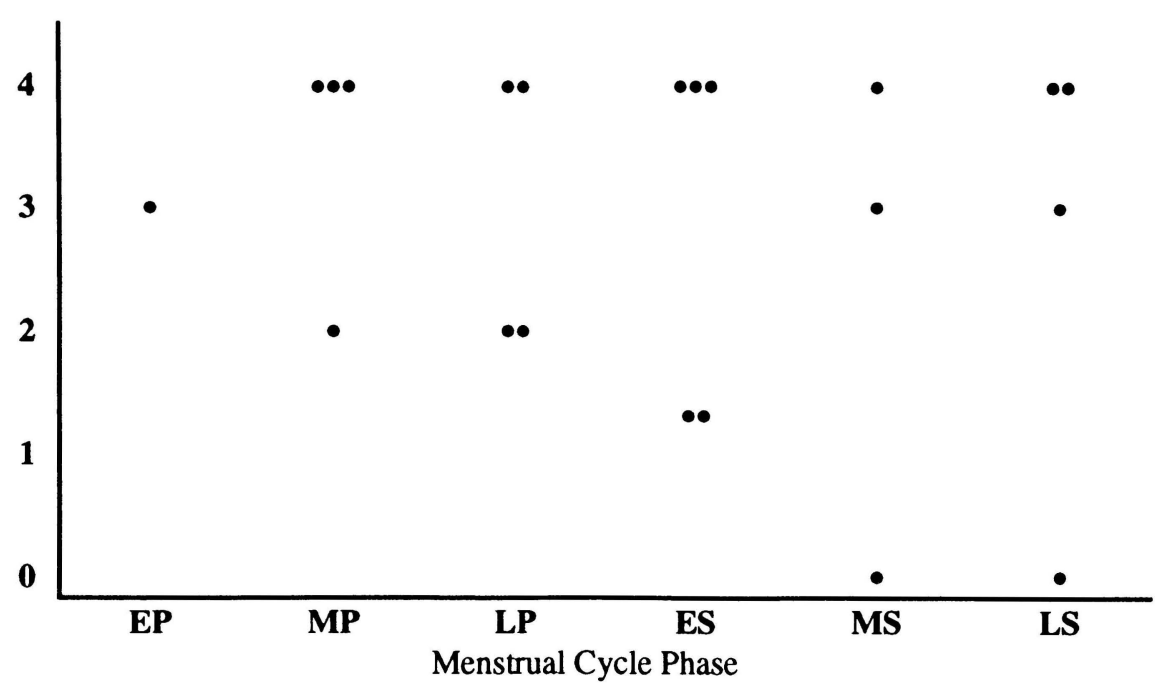

Figure 1. Schematic representation of pS2 antibody reactivity in the endometrium during the menstrual cycle. The degree of change in intensity and numbers of cells staining was graded according to a 5-point scale (see text); $\bullet$, number of cases

expression of $\mathrm{pS} 2$ was determined by an indirect streptavidin:biotin immunohistochemical technique using a second generation murine monoclonal antibody raised against affinity purified $\mathrm{pS} 2$ peptide (CIS-UK). Positive staining was graded according to a 5-point scale, taking into account the intensity of glandular staining and the proportion of stained cells. A score of 4 indicates intense staining of more than 95 per cent of glands, compared to a score of 1 which is indicative of occasional and/or weak glandular epithelial staining.

In contrast to the previous reports of $\mathrm{pS} 2$ expression in endometrium we have demonstrated pS2 in 19/21 (90 per cent) of cases with binding to glandular epithelium of the endometrium. The distribution of $\mathrm{pS} 2$ did not appear to show cycle phase specific expression (Figure 1). Indeed intense staining was observed in endometrial tissues from all stages of the menstrual cycle. Staining was localized at the luminal membrane of the glandular epithelium (Figure 2), with cytoplasmic reactivity limited to those areas adjacent to the gland luminal membrane. No stromal reactivity was observed at any stage of the cycle.

Our results of $\mathrm{pS} 2$ expression in normal endometrium are contrary to the findings of other studies using antibodies (Piggot et al. 1991) and mRNA approaches (Rio et al. 1988; Chambon et al. 1984). The inability to detect $\mathrm{pS} 2 \mathrm{mRNA}$ may have been due to a low glandular/stromal cell ratio in the tissues analysed. Moreover, the immunohistochemical approach of Piggot et al. (1991) used antibodies raised against different parts of the pS2 peptide. The immunohistochemical distribution of pS2 detected by these antibodies were notably different from our findings: only diffuse cytoplasmic staining was observed with no membrane localization.

The expression of $\mathrm{pS} 2$ in the endometrium, as identified in this study, does not show a menstrual cycle phase-specific pattern concordant with that of an oestrogenregulated peptide. These findings suggest that the oestrogen-induced $\mathrm{pS} 2$ peptide as 

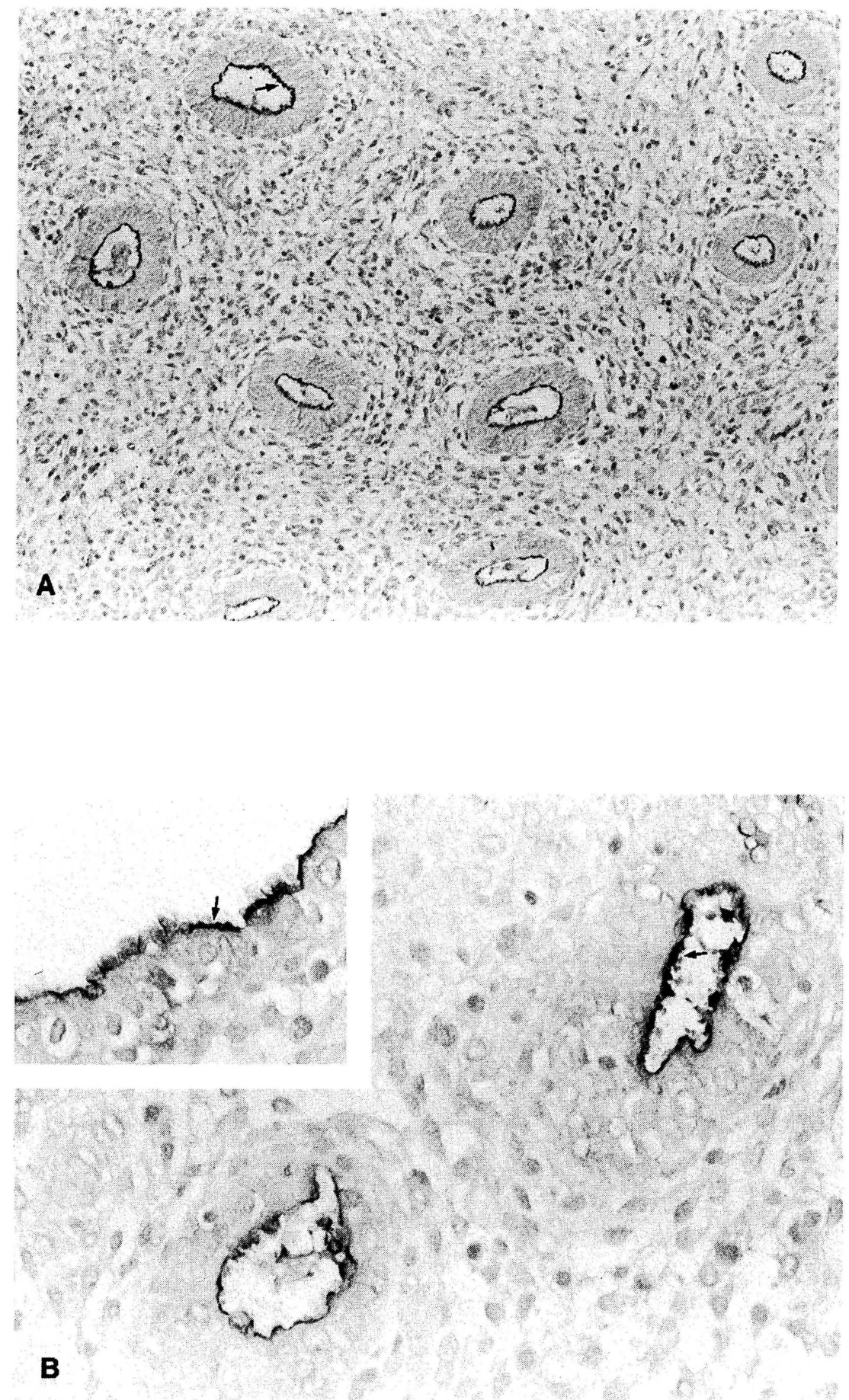

Figure 2. Photomicrographs of glandular endometrium from the proliferative (A) and secretory (B) phases of the menstrual cycle showing strong reactivity of the pS2 antibody localized at the glandular luminal membranes (arrowed). Antibody reactivity was also localized at surface endometrium (inset) 
expressed in normal endometrium is dependent on other additional factors. Indeed this supports other recent studies in breast which have demonstrated that DNA enhancer elements flanking the $\mathrm{pS} 2$ gene are responsive not only to oestrogen but also the epidermal growth factor (EGF), a tumour promoter (TPA), and the c-Haras and c-jun oncoproteins (Nunez et al. 1989). In gastric mucosa EGF has also been shown to directly induce $\mathrm{pS} 2$ secretion (Wright et al. 1991). Recent reports indicate that this oestrogen-independent expression of $\mathrm{pS} 2$ is the result of a shared signal transduction pathway linking different stimulatory agents to elevated pS2 gene expression (Wysocki et al. 1990). Indeed, perhaps the induction of pS2 occurs by a mechanism similar to that involved in the spatial summation of action potentials in the transmission of nerve impulses.

Since the expression of pS2 does not follow a controlled pattern during the secretory phase it is unlikely to be of value as a marker of the functional state of endometrium in its readiness for implantation. Although pS2 does not appear to be of use in this respect, its expression in endometrium does shed some light on its possible function as a regulator of cell proliferation: the expression of $\mathrm{pS} 2$ in normal endometrial tissue may serve to modulate proliferation in the menstrual cycle. The high level of expression observed throughout the cycle in 90 per cent of those cases studied, and the absence or weak expression of $\mathrm{pS} 2$ detected in endometrial adenocarcinomas (Henry et al. 1991; Wysocki et al. 1990), would appear to support this theory. Although earlier reports concerning the induction of the pS2 peptide by oestrogen found that it was not involved in the growth-stimulating effect of oestrogen in the MCF-7 breast cancer cell line (Davidson et al. 1986; Kida et al. 1989), this does not preclude the possible role of $\mathrm{pS} 2$ in modulating proliferation by an oestrogen-independent pathway. This theory of pS2's functional role is further supported by its structural similarity with several peptide growth factors such as insulin-like growth factor-I and porcine spasmolytic polypeptide (PSP) (Rio et al. 1988; Baker, 1988; Mori et al. 1988). Indeed it has been suggested that pS2 belongs to a new family of growth factors (Thim, 1989).

The localization of pS2 at the apical membrane of normal glandular endometrium would suggest that it may function by a paracrine mechanism. A diagrammatic summary of the known and postulated interactions and mechanisms of pS2 induction is shown in Figure 3.

The $\mathrm{pS} 2$ peptide may also act in a protective role by modulating the expression of mucins. The structural similarity of $\mathrm{pS} 2$ with EGF, PSP/hSP, and carbohydrate catabolic enzymes (Tomasetto et al. 1990) indicates some involvement in this function. Moreover, recent studies have detected pS2 in mucous secreting cells of the normal gastric mucosa (Piggot et al. 1991), gastric carcinomas (Henry et al. 1991), and in mucinous gynaecological adenocarcinomas (Wysocki et al. 1990). The detection of pS2 in normal endometrium identified by us further supports this functional role.

We suggest that in human endometrial tissue during the menstrual cycle the pS2 peptide may serve in a protective and/or proliferative role through its modulation of mucin/glycoconjugate expression. In addition we suggest that the expression of $\mathrm{pS} 2$ in this tissue reflects the complex multifunctional actions of the agents involved in its induction. Further study involving the interaction of these agents in their role of pS2 induction is required to fully understand the functional nature of the pS2 peptide. 


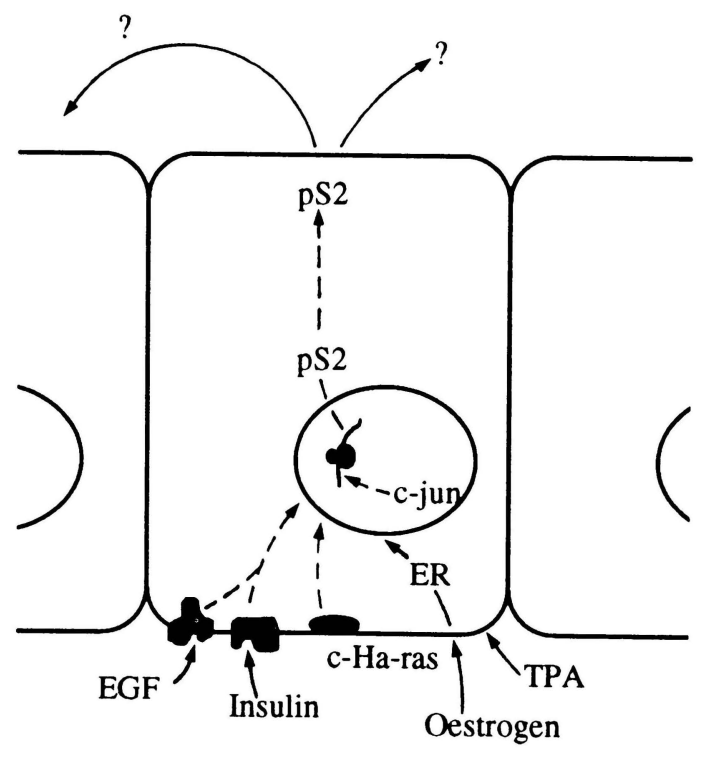

Figure 3. Diagrammatic summary of the interactions and mechanisms of $\mathrm{pS} 2$ induction in relation to its proposed function

\section{ACKNOWLEDGEMENTS}

This work was supported by the Cancer Research Campaign. We thank Dr S.C. Bell for the provision of tissues.

\section{REFERENCES}

Baker, M.E. (1988) Oestrogen-induced pS2 protein is similar to pancreatic spasmolytic polypeptide and the kringle domain. Biochem. J., 253, 307-311.

Brown, A.M.C., Jeltsch, J.M., Roberts, M., Chambon, P. (1984) Activation of pS2 gene transcription is a primary response to oestrogen in the human breast cancer cell line MCF-7. PNAS USA, 81, 6344-6348.

Chambon, P., Dierich, A., Gaub, M.P., Jakowlev, S., Jongstra, J., Krust, A., Le Pennec, J.P., Oudet, P., Reudelhuber, T. (1984). Promoter elements of genes coding for proteins and modulation of transcription by oestrogens and progesterone. Recent Prog. Hormone Res., 40, $1-42$.

Davidson, N.E., Bronzert, D.A., Chambon, P., Gelmann, E.P., Lippman, M.E. (1986). Use of two MCF-7 cell variants to evaluate the growth regulatory potential of oestrogen induced products. Cancer Res., 46, 1904-1908.

Hendrickson, M.R., Kempson, R.L. (1980). Surgical Pathology of the Uterine Corpus. Philadelphia: W.B. Saunders, pp. 36-98.

Henry, J.A., Bennett, M.K., Piggott, N.H., Levett, D.L., May, F.E.B., Westley, B.R. (1991). Expression of the $\mathrm{pNR} / \mathrm{pS} 2$ protein in diverse human epithelial tumours. Br. J. Cancer, 64, $677-682$.

Kida, N., Yoshimura, T., Mori, K., Hayashi, K. (1989). Hormonal regulation of synthesis and secretion of $\mathrm{pS} 2$ protein relevant to growth of breast cancer cells (MCF-7). Cancer Res., 49, 3494-3498. 
Masiakowski, P., Breathnach, R., Bloch, J., Gannon, F., Krust, A., Chambon, P. (1982). Cloning of cDNA sequences of hormone regulated genes from the MCF-7 human breast cancer cell line. EMBO J., 10, 7895-7903.

Mori, K., Fujii, R., Kida, N., Ohta, M., Hayashi, K. (1988). Identification of a polypeptide secreted by human breast cancer cells (MCF-7) as the human estrogen-responsive gene (pS2) product. Biochem. Biophys. Res. Commun., 155, 366-371.

Nunez, A.M., Berry, M., Imler, J.L., Chambon, P. (1989). The $5^{\prime}$ flanking regions of the pS2 gene contain a complex enhancer region responsive to oestrogens, epidermal growth factor, a tumour promoter (TPA), the c-Ha-ras oncoprotein and the c-jun protein. EMBO $J ., 8,823-829$.

Piggott, N.H., Henry, J.A., May, F.E.B., Westley, B.R. (1991). Antipeptide antibodies against the pNR-2 oestrogen-regulated protein of human breast cancer cells and detection of pNR-2 expression in normal tissues by immunohistochemistry. J. Pathol., 163, 95-104.

Rio, M.C., Bellocq, J.P., Daniel, J.Y., Tomasetto, C., Lathe, R., Chenard, M.P., Batzenschlager, A., Chambon, P. (1988). Breast cancer-associated pS2 protein: synthesis and secretion by normal stomach mucose. Science, 241, 705-708.

Rye, P.D., Bell, S.C., Walker, R.A. (1993). Immunohistochemical expression of tumourassociated glycoprotein and polymorphic epithelial mucin in the human endometrium during the menstrual cycle. J. Reprod. Fert., in press.

Thim, L. (1989). A new family of growth factor-like peptides. FEBS Lett., 250, 85-90.

Tomasetto, C., Rio, M.C., Gautier, C., Wolf, C., Hareuveni, M., Chambon, P., Lathe, R. (1990). hSP the domain duplicated homologue of $\mathrm{pS} 2$ protein is co-expressed with stomach but not in breast carcinoma. EMBO J., 9, 407-414.

Wright, N.A., Poulsom, R., Stamp, G.W.H., Hall, P.A., Jeffery, R.E., Longcroft, J.M., Rio, M.C., Tomasetto, C., Chambon, P. (1990). Epidermal growth factor (EGF/URO) induces expression of genes encoding regulatory peptides in damaged human gastrointestinal tissues. J. Pathol., 162, 279-284.

Wysocki, S.J., Hahnel, E., Masters, A., Smith, V., McCartney, A.J., Hahnel, R. (1990). Detection of pS2 messenger RNA in gynaecological cancers. Cancer Res., 50, 1800-1802. 


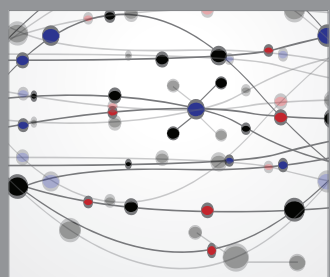

The Scientific World Journal
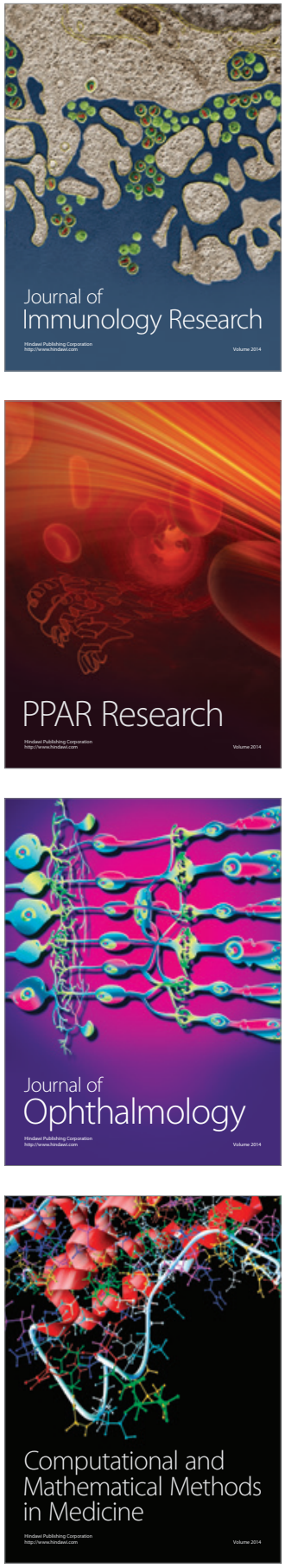

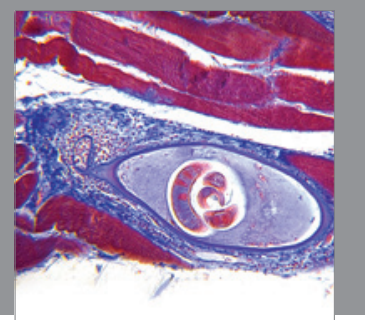

Gastroenterology

Research and Practice
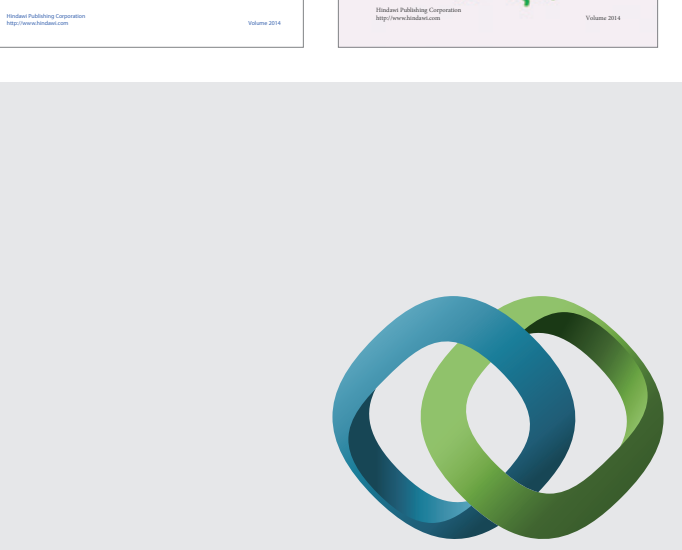

\section{Hindawi}

Submit your manuscripts at

http://www.hindawi.com
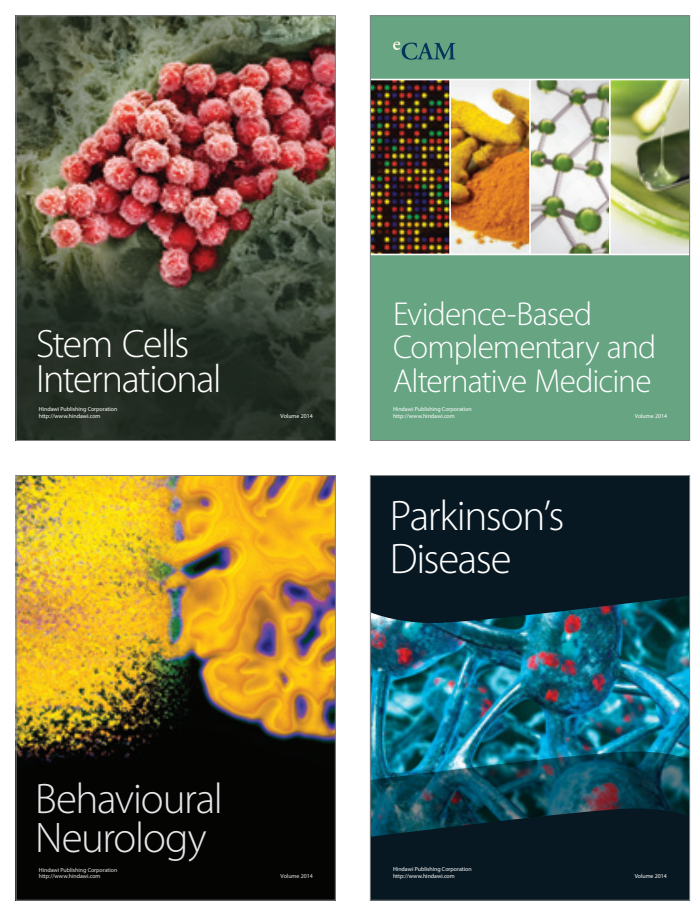

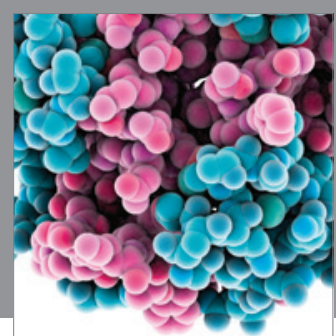

Journal of
Diabetes Research

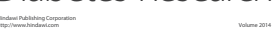

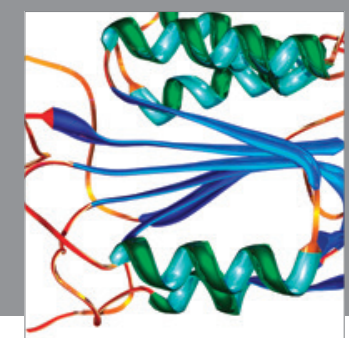

Disease Markers
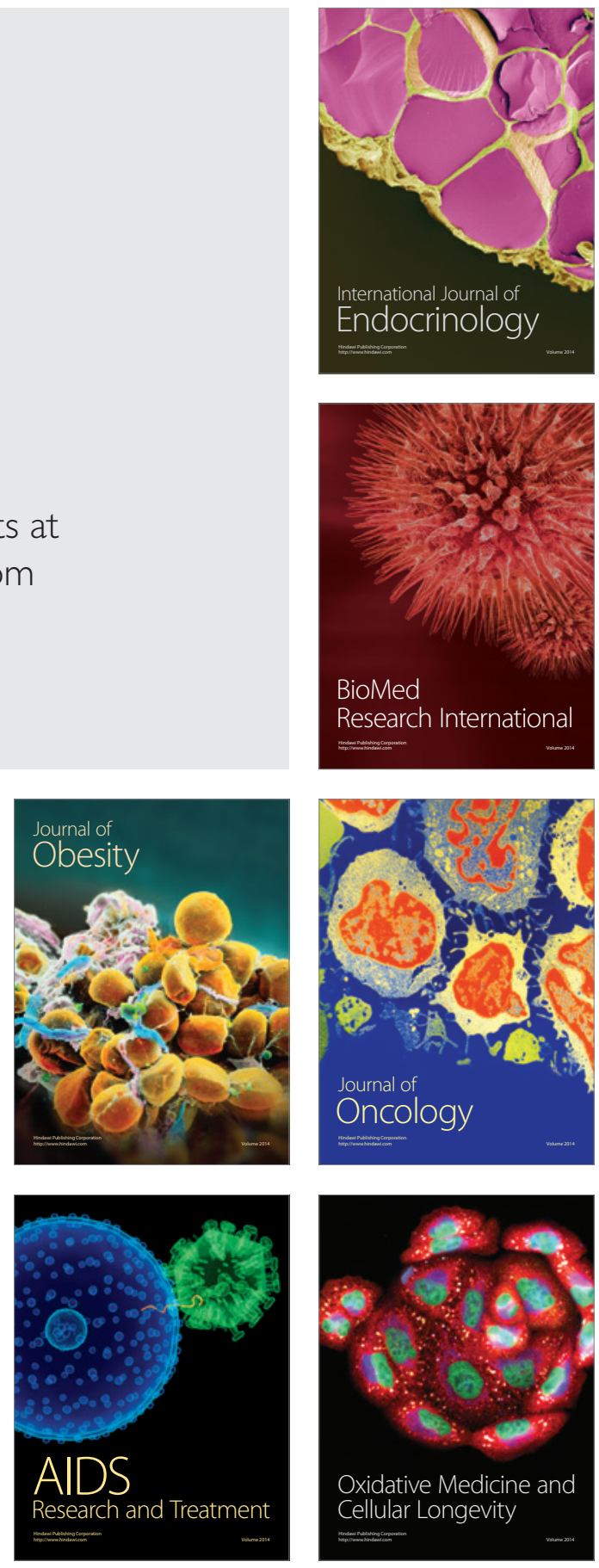